\title{
Anatomical Variations of the Foramen Magnum, Occipital Condyle and Jugular Tubercle
}

\author{
Foramen Magnum, Oksipital Kondil ve Juguler Tüberkülün Anatomik \\ Varyasyonları
}

Emel AVCI ${ }^{1}$, Ahmet DAGTEKIN ${ }^{1}$, A. Hakan OZTURK ${ }^{2}$, Engin KARA ${ }^{3}$, Nail Can OZTURK ${ }^{2}$, Kutluay ULUC ${ }^{4}$, Erinc AKTURE ${ }^{4}$, Mustafa K. BASKAYA ${ }^{4}$

${ }^{1}$ Mersin University, Faculty of Medicine, Department of Neurosurgery, Mersin, Turkey

${ }^{2}$ Mersin University, Faculty of Medicine, Department of Anatomy, Mersin, Turkey

${ }^{3}$ Mersin University, Faculty of Medicine, Department of Radiology, Mersin, Turkey

${ }^{4}$ University of Wisconsin and William S. Middleton Veterans Administration Hospital, Department of Neurological Surgery, Madison,

Wisconsin, USA

Correspondence address: Mustafa K. BASKAYA / E-mail: m.baskaya@neurosurg.wisc.edu

\section{ABSTRACT}

AIM: The foramen magnum (FM) is a unique and complex anatomical region. The occipital condyle (OC) and jugular tubercle (JT) are the main bony structures which obscure the anterolaterally situated lesions of the FM.The aim of this study was to revisit the anatomy of the FM region and assess variations of the surrounding structures.

MATERIAL and METHODS: Observations, on thirty dry skulls (dried specimens, 60 sides) and ten formalin-fixed cadaveric heads with perfused vessels, were carried out to define the microsurgical anatomy of the FM region. Morphometric analysis and variations of the FM, OC, JT and hypoglossal canal $(\mathrm{HC})$ were noted. Radiological assessment (3D-computed tomography) of the OC, JT, HC were also conducted on dry skulls. RESULTS: The short and long OC were demonstrated in 5\% and 33\% of the specimens, respectively. Flat formation of the JT was determined in $10 \%$ and tall JT was found in $23 \%$ of the specimens. The comparison of the anatomical measurements and the correspondent radiological mean values did not achieve statistical significance.

CONCLUSION: The OC and JT are the main bony prominences obstructing the anterolateral surface of the brainstem. Neurosurgeons should be familiar with variations of the structures surrounding the FM in order to perform the safest and widest exposure possible.

KEYWORDS: Foramen magnum, Occipital condyle, Jugular tubercle, Skull base, Anatomical variations

öz

AMAÇ: Foramen magnum (FM) karmaşık yapıya sahip anatomik bir bölgedir. FM kaynaklı patolojiler yüksek mortalite ve morbidite ile seyreden cerrahi yaklaşım itibarı ile zor lezyonlardır. Oksipital kondil ve juguler tüberkül foramen magnum anterolateralinde yerleşen lezyonlara erişimi engelleyen ana kemik yapılardır. Oksipital kondil (OK) ve juguler tüberkül (JT) rezeksiyonu ile cerrahi sahanın daha rahat erişilebilirliğini bildiren çeşitli yayınlar mevcuttur. Çalışmamızın amacı FM bölgesinin tekrar betimlenmesi ve komşu yapıların varyasyonlarını gözden geçirmektir.

YÖNTEM ve GEREÇ: FM mikrocerrahi anatomisi 30 kuru kafa (60 taraf) ve silikon ile doldurulmuş formalin ile fikse edilmiş 10 kadavrada çalışılmıştır. Morfometrik analizler, FM, OK, JT ve hipoglossal kanal (HK) varyasyonları belirlenmiştir. Kuru kafalarda OK, JT ve HK'ın 3 boyutlu radyolojik değerlendirmesi yapılmıştır. Kadavralarda far lateral transkondiler yaklaşım gerçekleştirilmiştir.

BULGULAR: Spesimenlerde kısa ve uzun OK sırasıyla \%5 ve \%33 olguda gözlenmiştir. Yine, JT'nin düz formasyonu \%10, yüksek formasyonu ise \%23 olguda mevcuttur. Anatomik ölçümler ve karşılık gelen radyolojik ortalama değerlerin karşılaştırmasında istatistiksel fark gözlenmemiştir. SONUÇ: OK ve JT, beyin sapının anterolateral yüzeyini örten ana kemik yapılardır. Beyin cerrahları, en güvenli ve geniş cerrahi açılımı yapabilmek için FM çevresindeki yapıların varyasyonlarına hakim olmalıdırlar.

ANAHTAR SÖZCÜKLER: Foramen magnum, Oksipital kondil, Juguler tüberkül, Kafa kaidesi, Anatomik varyasyon 


\section{INTRODUCTION}

The occipital bone can be described as being perforated by the FM with the squamous part behind the foramen, the condylar parts lateral and the basilar part in front and carries a great importance in the performance of far lateral approaches due to its localization and the foramina of this region. The anterolateral aspect of the FM is one of the deepest and most complex areas of the skull base. Exposure of intra- or extra-dural lesions involving the FM and brainstem poses a significant surgical challenge for neurosurgeons since the FM is covered by thick bony prominences where many cranial nerves or vascular structures pass through. Advances in skull base approaches (far lateral transcondylar and its modifications) have improved the angle of surgical exposure leading to better and wider access for successful surgery $(2,20,22,24)$. However, far lateral transcondylar approaches require extensive dissection of the paravertebral muscles and vessels, in particular, the vertebral artery and removal of bony structures such as the occipital condyle (OC) and jugular tubercle (JT). These maneuvers may result in injury to the vascular structures (vertebral artery, jugular vein and bulb) and lower cranial nerves and result in craniocervical instability due to removal of the OC. Hence, neurosurgeons performing this surgery should be more familiar with the anatomy and variations of this region. Therefore, anatomical morphometric studies $(2,4,6,14,15,18)$ and radiological investigations (17) were performed to contribute to the knowledge of this area. Both radiological and complementary anatomical investigations were also reported in the related literature (12). It is still imperative to have both radiological and anatomical measurements and the comparison of the findings to contribute for the better delineation of this subject. In the present study, we revisited the anatomy of the FM region, in particular its variations, which may affect the surgical route taken to perform lesions involving this region.

\section{MATERIAL and METHODS}

Ten formalin-fixed human cadaver heads (eight man, two woman; age range 23-68 years) were injected with colored silicone. Far lateral transcondylar approaches were performed bilaterally (20 sides) and microsurgical anatomical dissections were made under operative microscopic illumination and magnification (Leica, Wild M 695 surgical microscope, $x 3$ to $x 40)$. The following measurements in the region of the FM were carried out on 30 dry skull ( 60 sides) with digital calipers. The information regarding the exact age and the gender of the dry skulls that are taken from the archives of the Mersin University Medical Faculty Department of Anatomy is not known.

Anatomical Measurements: 1) The length and width of the OC, 2) the length, width and height of the JT 3) transverse and anteroposterior diameters of the FM, and the FM index which was calculated by dividing the anteroposterior diameter by the transverse diameter of the FM 4) protrusion of the OC into the $\mathrm{FM}, 5$ ) presence of posterior condylar foramen, 6 ) septation of the $\mathrm{HC}, 7$ ) distance of the $\mathrm{HC}$ from the posterior border of the OC, 8) distance of posterior border of the OC from opisthion and distance of anterior border of $O C$ from basion.

Radiological Measurements: Measurements were done (60 sides) similar to the anatomic bone assessments with axial, sagittal and coronal scans (Toshiba scanner; Aquillion 64 detectors, with technical parameters included $0.5 \mathrm{~mm}$ thick slices, $0.3 \mathrm{~mm}$ interval, FOV: $240 \mathrm{~mm}$, matrix: $512 \times 512$, pixel size: $0.46 \mathrm{~mm}, 230 \mathrm{~mA}, 120 \mathrm{kV}$ ). Scanning data were transferred to a work station with 3D visualization software (Silicon Graphics; Vitrea, Minneapolis, MN). We did not have a scanning arrangement at the beginning of imaging. We did our best to have the imaging views as symmetrical as possible by placing the skulls in a very careful manner in the gantry. After the establishment of the symmetrical raw data, images were reformatted in the work station. The measurement points were defined on the 3D reformatted image and their correspondent arrows were confirmed on the axial, sagittal and coronal planes. The best position to get the most accurate measurement was ensured by rotating the 3D reformatted image and checking the correspondent axial, sagittal and coronal views.

Statistical Analysis: The 'Paired Samples $t$ Test' was used to evaluate the mean differences of the measured parameters of the right and left sides. A comparison was performed between the right and left sides regarding symmetrical structures and $p<0.05$ was considered as statistically significant. Mean values, standard deviation and the range were all taken into consideration in the statistical analysis.

\section{RESULTS}

The average anteroposterior length and transverse diameter of the FM were found to be $34.5 \mathrm{~mm}$ and $29 \mathrm{~mm}$, respectively. The FM index is calculated by dividing the anteroposterior length by the tranverse diameter. When the FM index is $\geq$ 1.2 , the foramen is accepted to be ovoid. An ovoid FM was found in $58 \%$ of the specimens (Figure $1 \mathrm{~A}$ ). An asymmetrical FM were found in three specimens (10\%) (Figure 1B). The hypocondylar arch was present in one of the dry skulls (Figure 2), and was situated extracranially at the anterior margin of the FM. Its location ventral to the developing vertebral body, at an early embryonic stage, was reported by von Torklus and Gehle (25). The hypocondylar arch regresses and eventually disappears at birth with the exception of $\mathrm{C} 1$, which forms the anterior arch of the atlas. The hypocondylar arch may be retained after birth and is considered to be a manifestation of an occipital vertebra (25).

The OC protruded into the FM in $57 \%$ of the skulls examined, (Figure 3 ). There was no statistically significant difference in the distance between the anterior border of the $\mathrm{OC}$ and the basion on the right and left sides, nor was there any statistical difference in the distance between the posterior border of the $\mathrm{OC}$ and the opisthion on the right and left sides.

The condylar fossa was located at the posterior external surface of the condyle where the posterior condylar emissary 
vein often passes from the posterior condylar canal (Figure 4A). The posterior condylar emissary vein connects the vertebral venous plexus via the sigmoid sinus and forms an alternative source of venous drainage when the venous flow into the sigmoid sinus-jugular complex is compromised. The posterior condylar foramen was absent unilaterally in $27 \%$ of the specimens and bilaterally in $17 \%$ of the specimens (Figure 4B). We found the posterior condylar foramen, when present, to be just lateral to the jugular process, located interiorly in the skull base.

The Radio-Anatomical Features of JT, OC and HC: The OC is an oval mass and forms the lateral limits of the craniovertebral junction (Figure 5A,B,C). The radiological and anatomical measurements of the $O C$ comparing the right and the left sides were not found to be statistically significant (Table I). The OC was classified according to its length as $<20 \mathrm{~mm}$ (short), 20-26 mm (moderate), or $>26 \mathrm{~mm}$ (long) (15). In this study, the incidences of short, moderate and long $O C$ were found to be $5 \%, 62 \%$, and $33 \%$, respectively (Figure $6 \mathrm{~A}, \mathrm{~B}$ ). It was observed that the morphology of the two condyles were rarely symmetrical (Figure 6C). The JT was located anterosuperior to the $\mathrm{OC}$ and $\mathrm{HC}$ at the junction of the basilar and condylar portions of the occipital bone (Figure $7 A, B, C, D$ ). The jugular process acts as a bridge extending between the condylar and squamosal parts of the occipital bone. The jugular process was situated posterior to the JT. The variability in the height of the JT was carefully evaluated through its measurements as there were no exact anterior and posterior landmarks of the JT and the configuration was highly variable. Statistical significance was not achieved when assessing the anatomical length, width and height of the JT and corresponding radiological values. The mean anatomical length, width and height of the JT were $15.4 \mathrm{~mm}, 9.6 \mathrm{~mm}$ and $7.7 \mathrm{~mm}$, respectively. The mean radiological length, width and height of the JT were $16.5 \mathrm{~mm}$, $9.5 \mathrm{~mm}$ and $6.8 \mathrm{~mm}$, respectively. In the present study, a tall JT (height $>8.5 \mathrm{~mm}$ ) was found in $23 \%$ of the specimens (Figure $8 \mathrm{~A}$ ) and a flat formation (height $<3.5 \mathrm{~mm}$ ) was found in $10 \%$ of the dry skulls (Figure 8B).
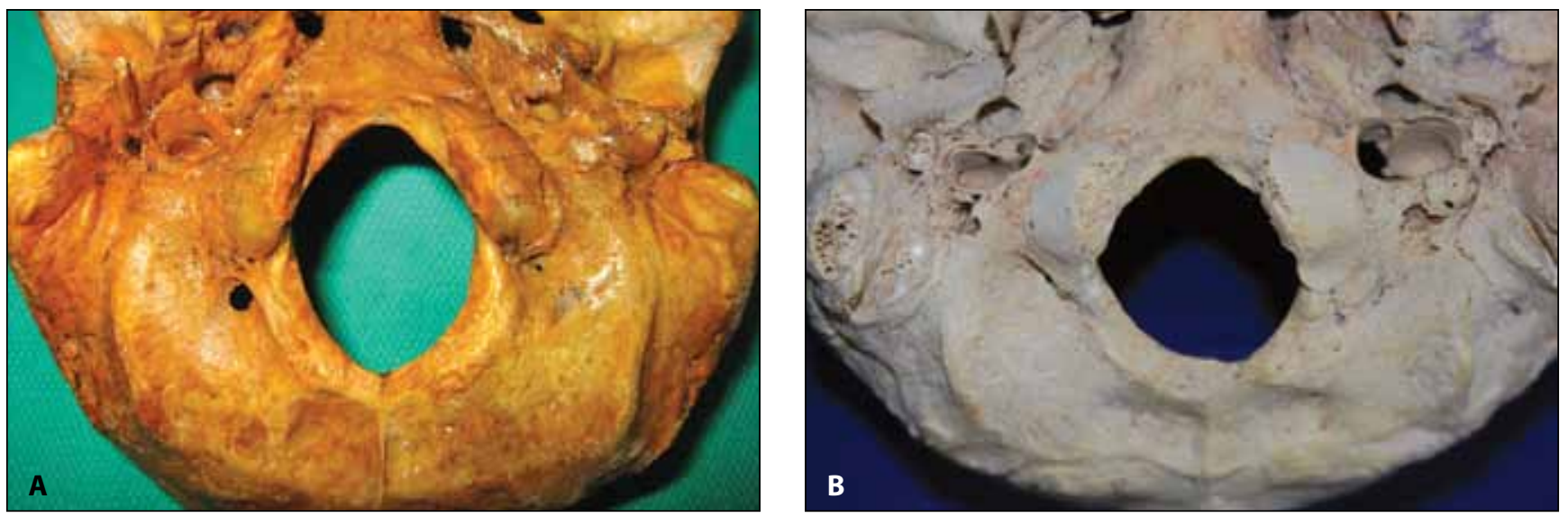

Figure 1: A) The ovoid type foramen magnum. B) Asymmetrical type foramen magnum.

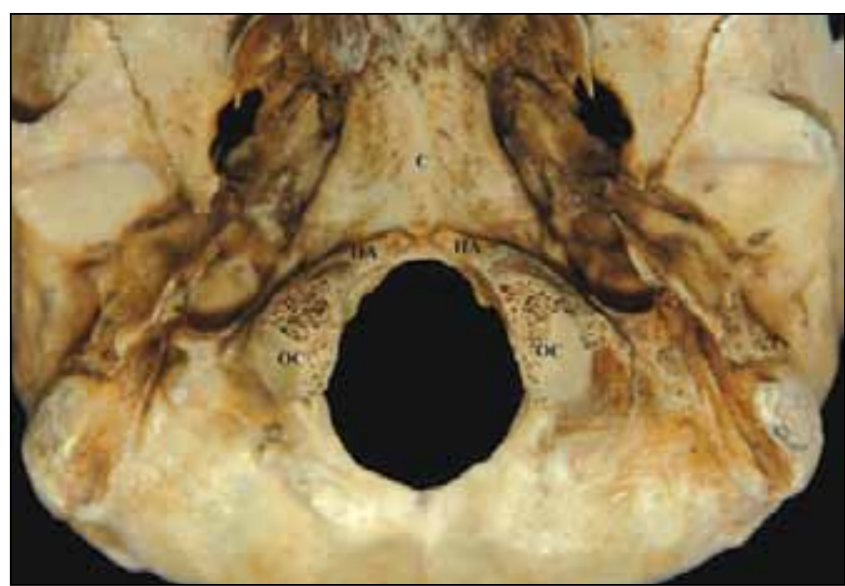

Figure 2: The hypocondylar arch between the two occipital condyles at the anterior margin of the foramen magnum. HA: Hypocondylar arch, OC: Occipital condyle, C: Clivus.

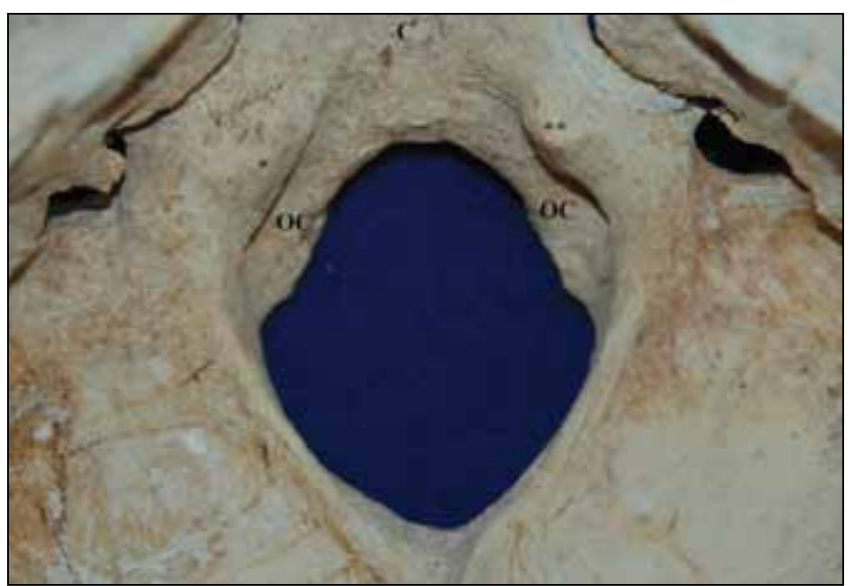

Figure 3: Protrusion of both occipital condyles into the foramen magnum. Also note the flat type of the jugular tubercle on the left. OC: Occipital condyle, C: Clivus, **: Right Jugular tubercle, *: Flat type of jugular tubercle on the left side. 

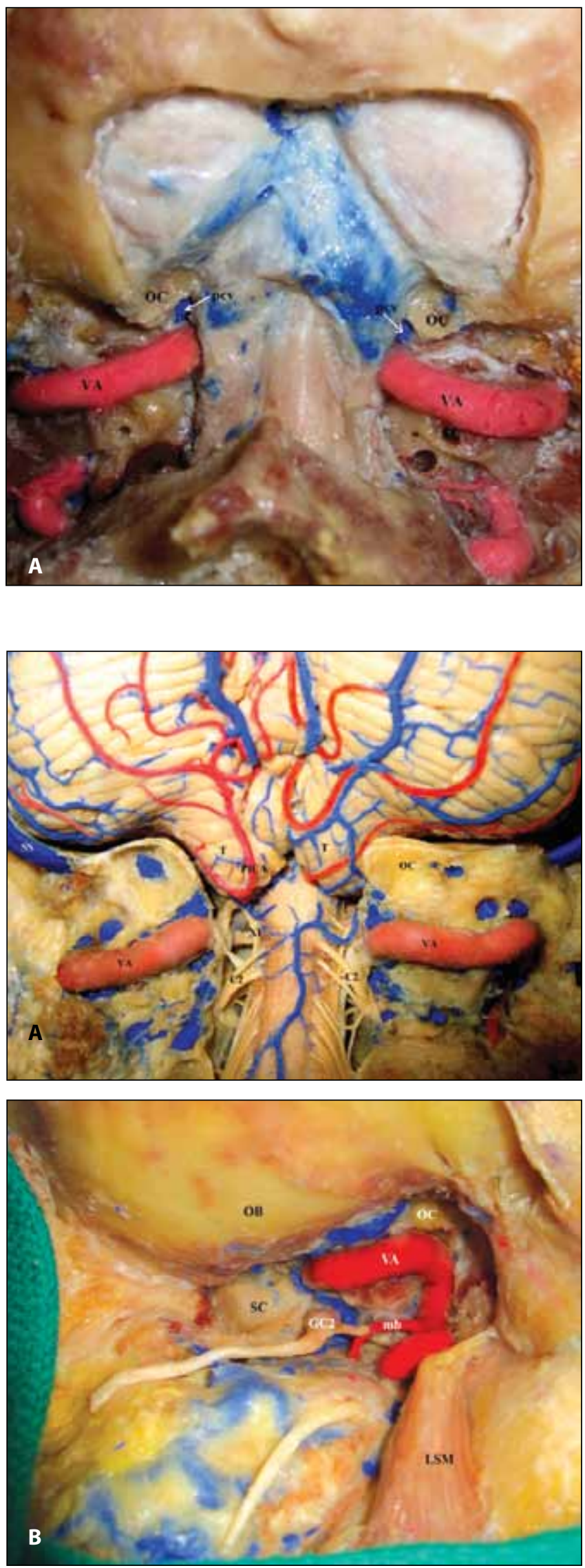

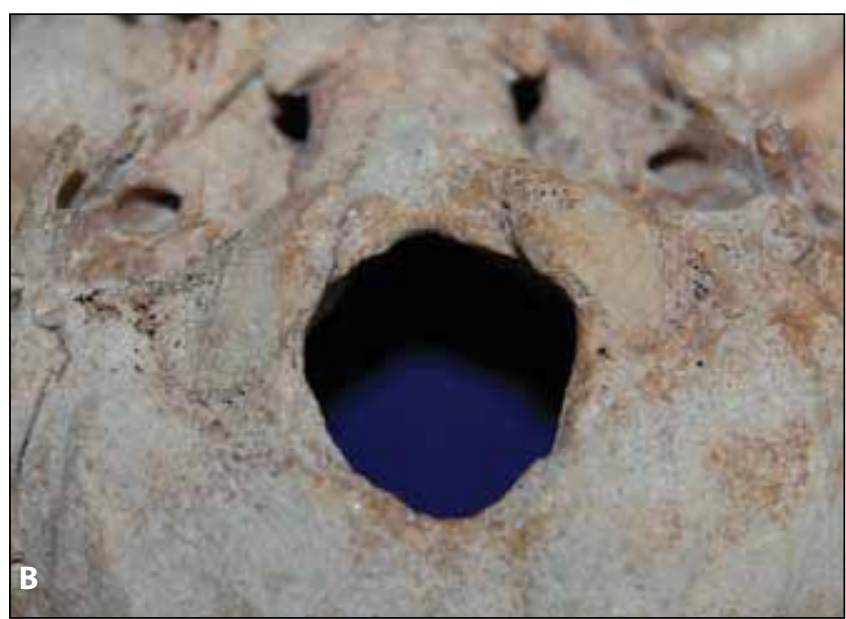

Figure 4: A) Median suboccipital craniotomy has been performed and $\mathrm{C} 1$ posterior arch has been removed. Both posterior condylar emissary veins have been demonstrated. VA: Vertebral artery, OC: Occipital condyle, pcv: Posterior condylar emissary vein. B) In this dry skull specimen, both posterior condylar foramina are absent.

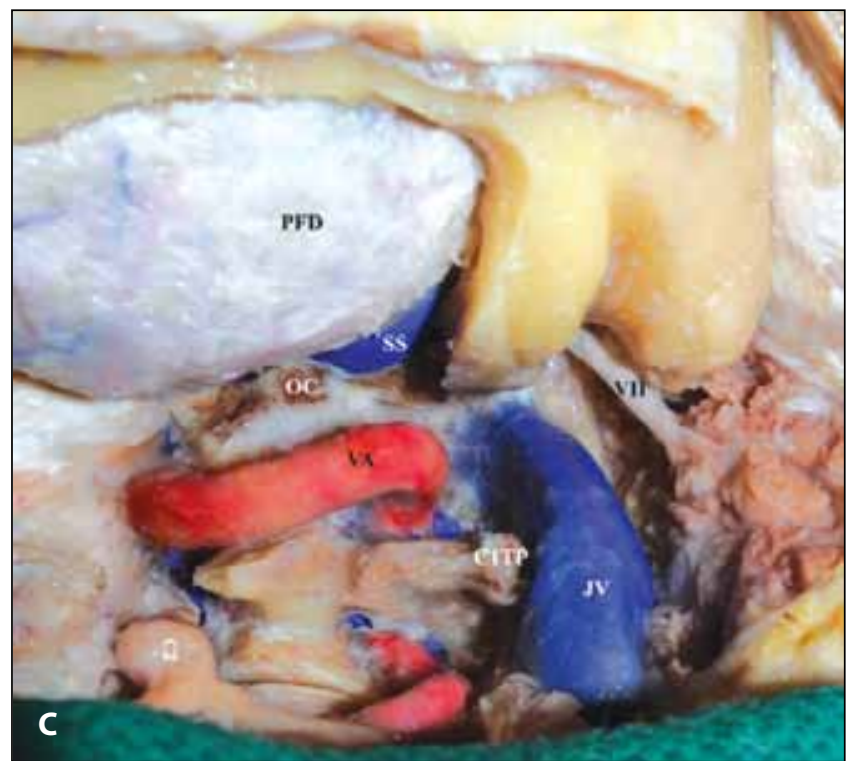

Figure 5: A) Cadaveric dissection shows the relationship between the occipital condyle and posterior part of the foramen magnum region structures. T: Tonsil, OC: Occipital condyle, PICA: Posterior inferior cerebellar artery, VA: Vertebral artery, XI: Accessory nerve, C2: C2 nerve. B) Cadaveric dissection shows the occipital condyle, vertical and horizontal segment of the vertebral artery. OB: Occipital bone, OC: Occipital condyle, VA: Vertebral artery, mb: Vertebral artery muscular branch, SC: Dura of the spinal cord, LSM: Levator scapulae muscle, GC2: Ganglion of (2. C) Suboccipital craniectomy has been performed and right half of the posterior arch of $\mathrm{C} 1$ has been removed. The occipital condyle has been exposed. SS: Sigmoid sinus, PFD: Posterior fossa dura, OC: Occipital condyle, JV: Jugular vein, VII: Facial nerve, VA: Vertebral artery, C1TP: C1 transverse process, C2: C2 nerve. 

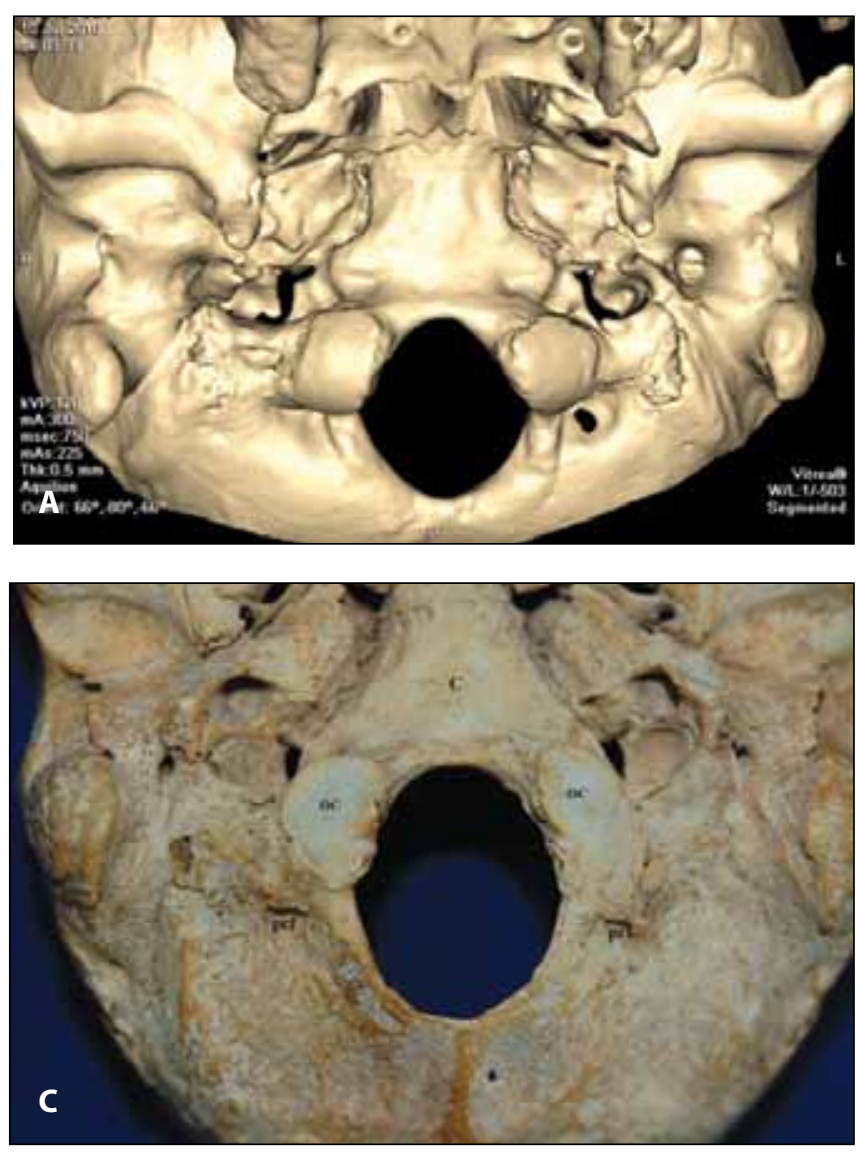

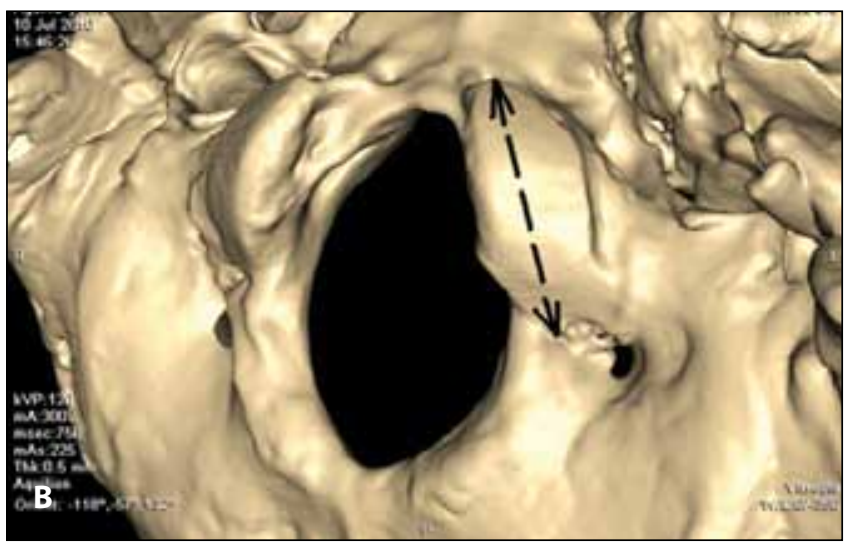

Figure 6: A) The 3D CT scan shows short occipital condyle. B) The 3D CT scan shows long occipital condyle. C) Morphometric variations of the occipital condyle in dry skull specimen. OC: Occipital condyle, C: Clivus, pcf: Posterior condylar foramen.

The $\mathrm{HC}$ is surrounded superiorly by the JT and inferiorly by the OC. It passes from a posteromedial to anterolateral direction. The $\mathrm{HC}$ was divided into two parts by a bony septum in $30 \%$ of the dry skulls (Figure 9). In this study, the HC was located at a mean distance of $9.9 \mathrm{~mm}$ from the posterior border of the $\mathrm{OC}$ in dry skull anatomical measurements, and $10.4 \mathrm{~mm}$ in 3D-CT measurements (Figure 10A, B). The data of measured parameters are summarized in Table $\mathrm{I}$.

Table I: The Measurements of Foramen Magnum Structures (Anatomical and Radiological)

\begin{tabular}{|c|c|c|c|c|c|c|}
\hline \multirow{2}{*}{ Parameters (mm) } & \multicolumn{3}{|c|}{ Right $(n=30)$} & \multicolumn{3}{|c|}{ Left $(n=30)$} \\
\hline & Range & Mean & p value & Range & Mean & p value \\
\hline Length of OC (Anatomical) & $18.2-28.7$ & $23.7 \pm 2.6$ & 0.4035 & $18.8-30.9$ & $24 \pm 2.7$ & 0.4035 \\
\hline Length of $O C$ (3D CT) & $18.7-2.4$ & $2.8 \pm 2.4$ & 0.5608 & $19.5-27.5$ & $23.9 \pm 2.0$ & 0.5608 \\
\hline Width of OC (Anatomical) & $9-14.5$ & $12.2 \pm 1.2$ & 0.1762 & $9.3-15.3$ & $12.4 \pm 1.5$ & 0.1762 \\
\hline Width of OC (3D CT) & $9.3-14.6$ & $12.0 \pm 1.3$ & 0.7115 & $9.8-15.3$ & $12.1 \pm 1.5$ & 0.7115 \\
\hline Length of JT (Anatomical) & $12.5-18.5$ & $15.4 \pm 1.24$ & 0.8004 & $12.5-19.4$ & $15.3 \pm 1.32$ & 0.8004 \\
\hline Length of JT (3D CT) & $14.7-18.6$ & $16.4 \pm 1.1$ & 0.2929 & $14.3-19.8$ & $16.7 \pm 1.4$ & 0.2929 \\
\hline Width of JT (Anatomical) & $6.8-11.8$ & $9.6 \pm 1.2$ & 0.8965 & $7-11.8$ & $9.5 \pm 1.2$ & 0.8965 \\
\hline Width of JT (Radiological) & $6.0-11.8$ & $9.5 \pm 1.2$ & 0.7010 & $7.3-12$ & $9.5 \pm 1.3$ & 0.7010 \\
\hline Height of JT (Anatomical) & $3-12.7$ & $7.8 \pm 2.3$ & 0.5447 & $3-12$ & $7.6 \pm 2.2$ & 0.5447 \\
\hline Height of JT (Radiological) & $3.1-9.5$ & $6.8 \pm 0.8$ & 0.8244 & $3.0-9.3$ & $6.7 \pm 1.1$ & 0.8244 \\
\hline HC-OCPB (Anatomical) & $7.9-12.2$ & $9.8 \pm 1.1$ & 0.8599 & $6.6-12.2$ & $9.9 \pm 1.4$ & 0.8599 \\
\hline HC-OCPB (Radiological) & $8.7-13.1$ & $10.4 \pm 1.07$ & 0.8004 & $9.1-12.3$ & $10.4 \pm 0.7$ & 0.8004 \\
\hline OCAB-B & $5-14$ & $9.9 \pm 1.9$ & 0.6357 & $5.6-13.3$ & $10 \pm 2.0$ & 0.6357 \\
\hline OCPB-O & $23.5-30.7$ & $26.6 \pm 1.8$ & 0.2109 & $22.6-33.6$ & $27.1 \pm 2.6$ & 0.2109 \\
\hline
\end{tabular}

OC: Occipital condyle, HC: Hypoglossal canal, JT: Jugular tubercle, OCPB: Occipital condyle posterior border, OCAB: Occipital condyle anterior border, B: Basion, 0: Opisthion 

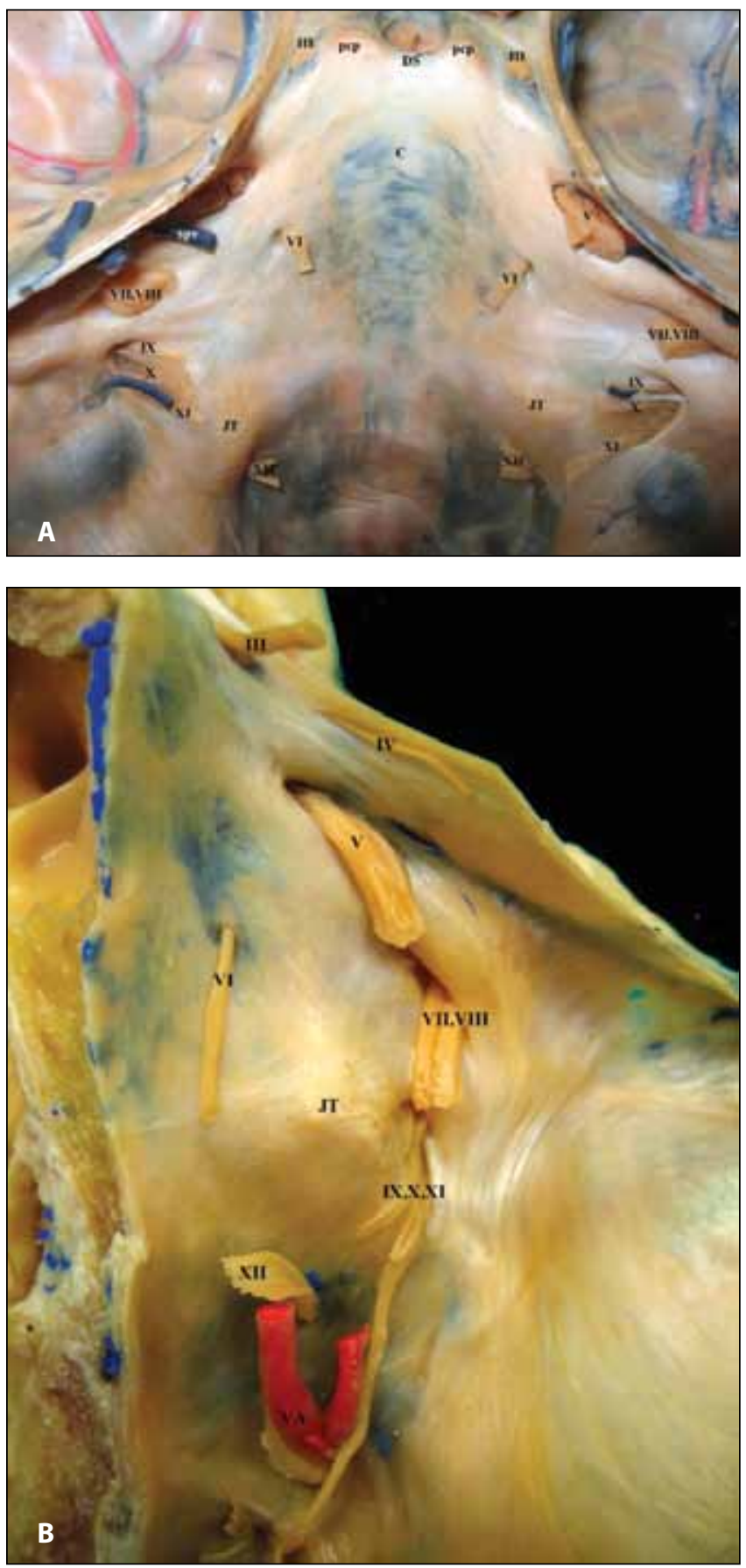

\section{DISCUSSION}

The far lateral transcondylar approach is a complex skull base approach that is used to reach the anterior and anterolateral aspects of the craniocervical junction, the FM and the brainstem (1-3,5,7-9,11-13,16,21,22,26) (Figure 11). There are many different terms used to describe this approach, and some of those include far lateral transcondylar, retrocondylar, supracondylar and condylar fossa approaches. Regardless of the terminology used, the main goal is the dissection and early extracranial exposure of the vertebral artery, lateral
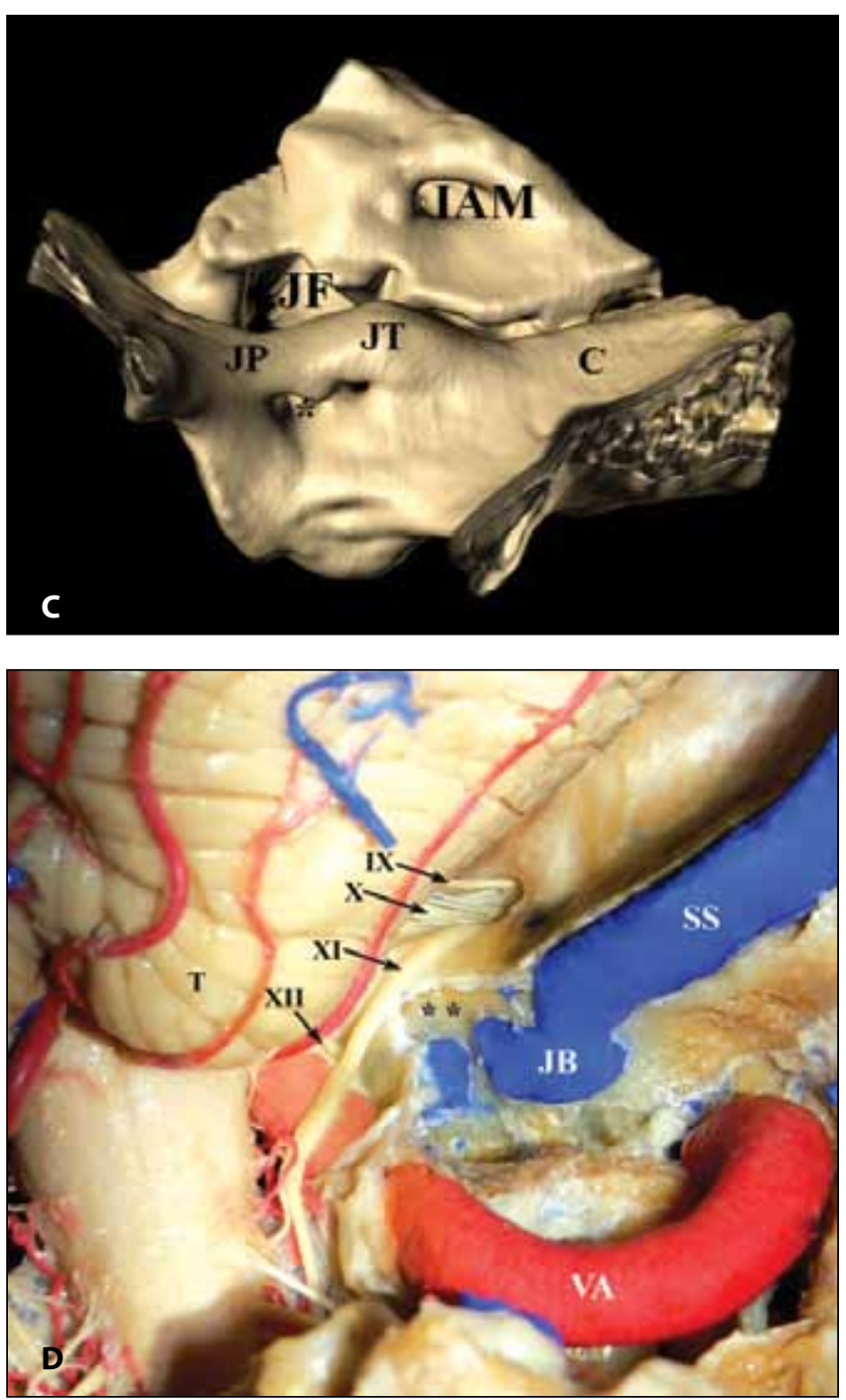

Figure 7: A-B) Overview of the lower cranial nerves, their foramina and jugular tubercle. Note the relationship of the JT and the hypoglossal canal. III: Oculomotor nerve, pcp: Posterior clinoid process, DS: Dorsum sellae, V: Trigeminal nerve, VI: Nervus abducens, VII: Facial nerve, VIII: Vestibulocohlear nerve, C: Clivus, JT: Jugular tubercle, IX: Glossopharyngeal nerve, $\mathbf{X}$ : Vagus nerve, XI: Accessory nerve, XII: Hypoglossal nerve. C) A 3D CT shows the JT and bony septum in the hypoglossal canal. JP: Jugular process, IAM: Internal acoustic meatus, C: Clivus, JF: Jugular foramen, JT: Jugular tubercle, *: Hypoglossal canal bony septum, D) Transcondylar approach has been performed, C1 posterior arch has been removed. Note the relationship of the JT and lower cranial nerves. IX: Glossopharyngeal nerve, X: Vagus nerve, XI: Accessory nerve, XII: Hypoglossal nerve. **: Jugular tubercle, T: Tonsil, VA: Vertebral artery, SS: Sigmoid sinus, JB: Jugular bulb.

suboccipital craniotomy and removal of the $O C$ and JT. The degree of resection of the OC and JT depends on the pathology, exact location and the microanatomical features and variations of bony prominences in the FM region $(2,6,8$ $10,12,13,16,20,23)$. In spite of many published studies on how much OC and/or JT should be removed, a question 

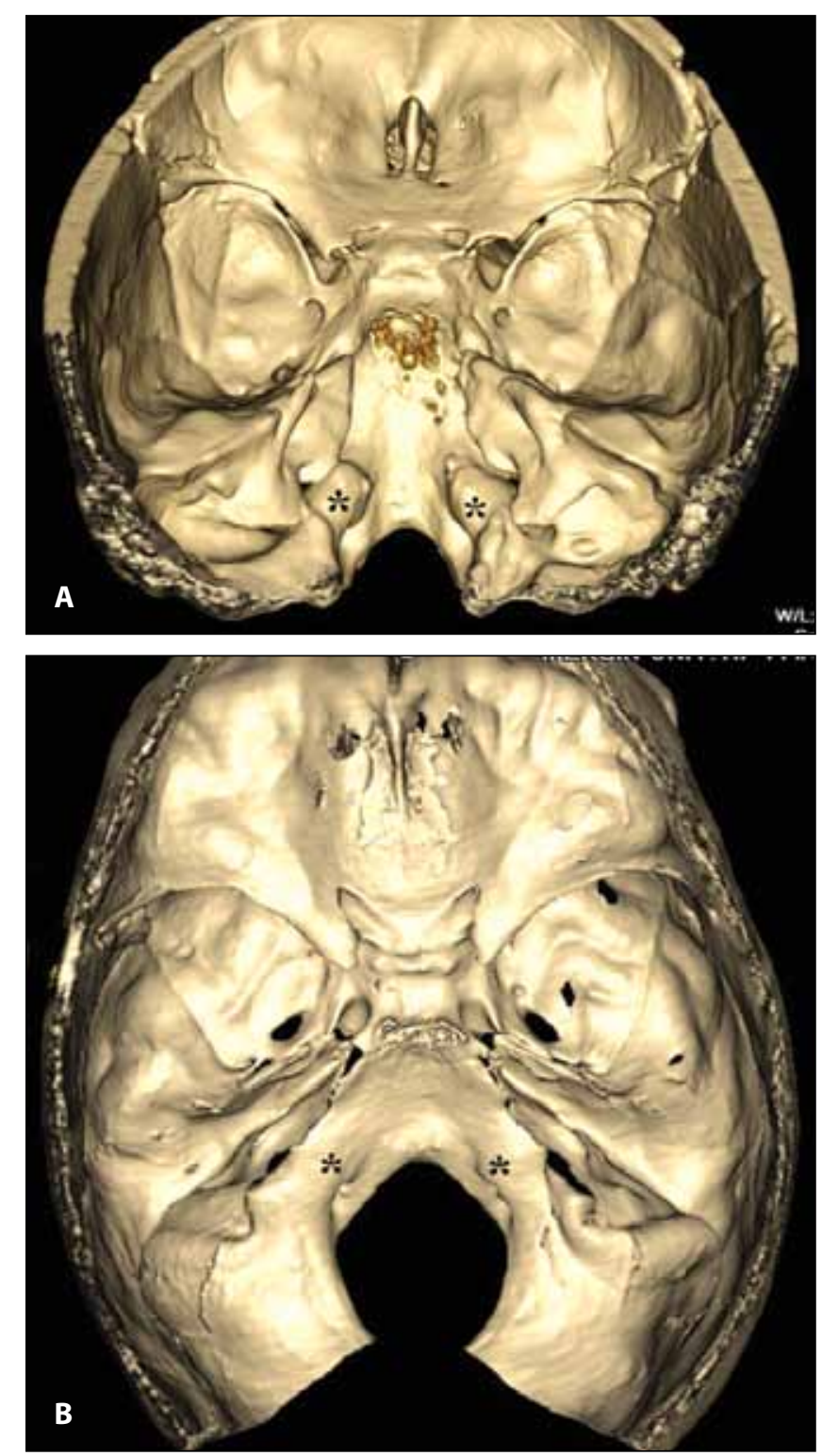

Figure 8: 3D CT scan shows bilateral tall JT, *: Jugular tubercle (A) and flat type of the JT, *: Jugular tubercle (B).

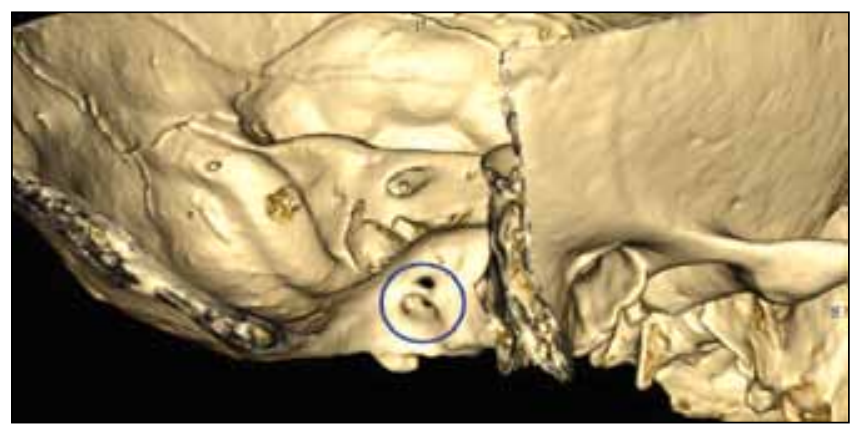

Figure 9: The hypoglossal canal region and the bony septation of the canal are shown on 3D CT.
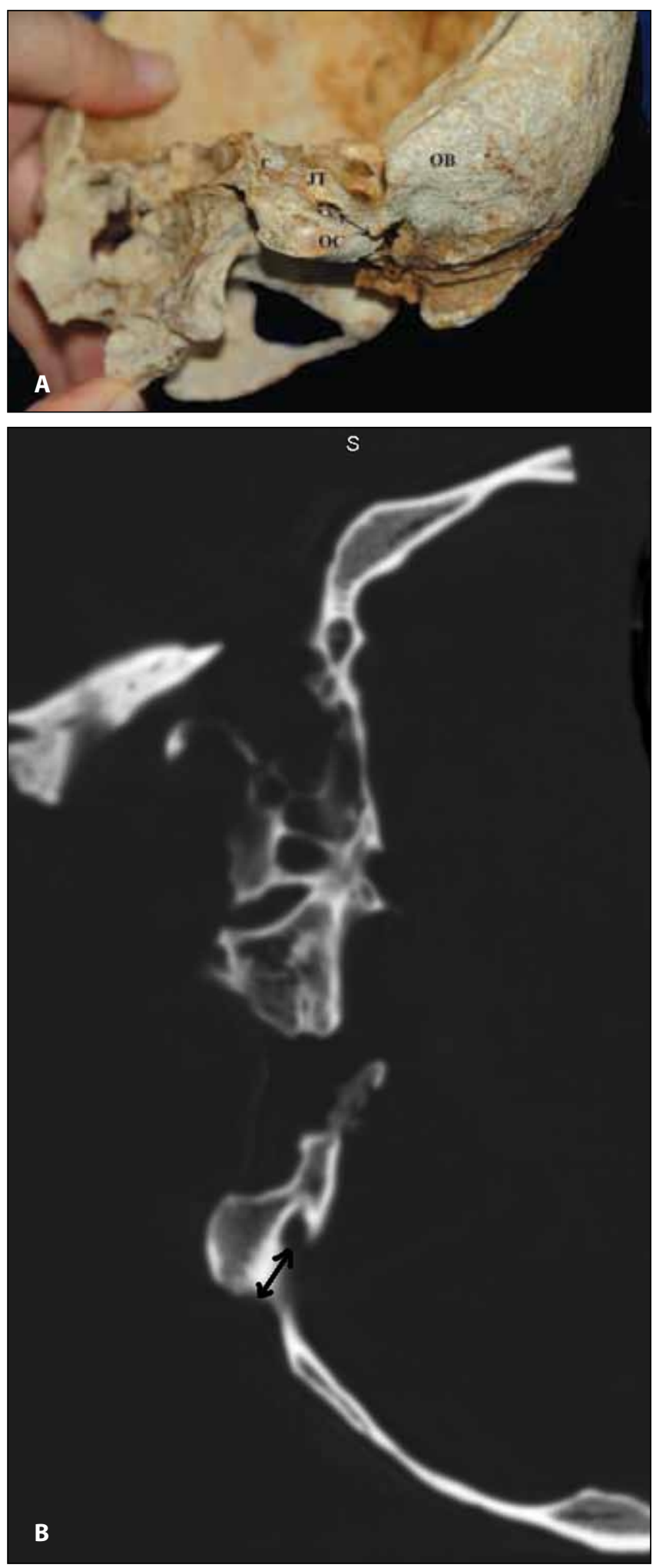

Figure 10: A) On a dry skull, demonstrated the method of measurement of $\mathrm{HC}$ and posterior border of the OC. C: Clivus, JT: Jugular tubercle, *: Hypoglossal canal, OB: Squamous portion of the occipital bone, OC: Occipital condyle. B) Sagittal slice of CT, demonstrated the method of measurement of $\mathrm{HC}$ and posterior border of the OC. 


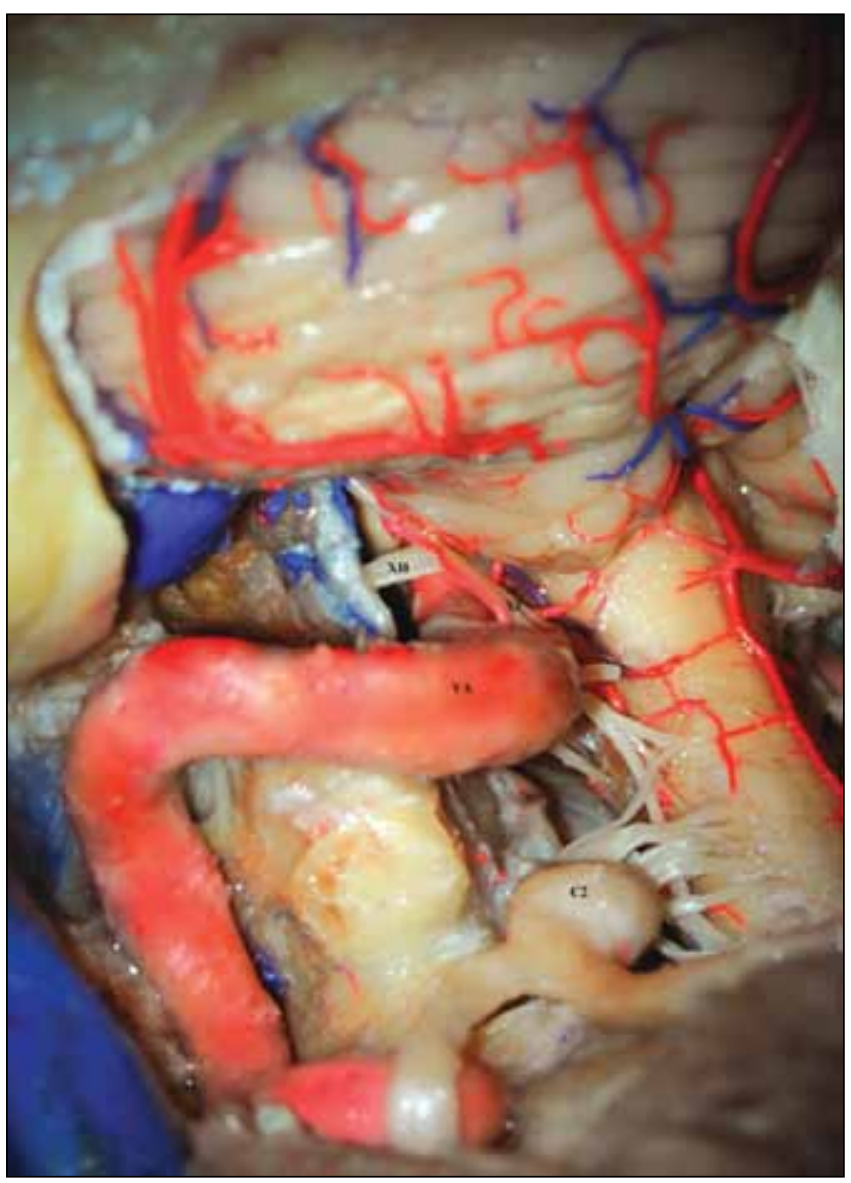

Figure 11: Overview after transcondylar approach has been performed. VA: Vertebral artery, C2: C2 ganglion, XI: Accessory nerve, XII: Hypoglossal nerve.

of whether or not removal of $O C$ increases the optimal visualization remains unanswered. Furthermore, drilling these bony prominences around critical structures may increase morbidity and mortality even in experienced hands.

According to Dowd et al. (7), the average length of the necessary OC resection to visualize the contralateral JT was found to be $17 \mathrm{~mm}$. Furthermore, this study reported that 2.4 degrees of extra visual angle was obtained for each 1 $\mathrm{mm}$ of condyle resection (8). Spektor et al. (23) reported that OC resection produced a $21 \%$ to $28 \%$ increase in visual angle for the petroclival region. The JT angle (JTA) was measured in a study of condylar fossa exposure in a cadaveric and 3D-CT study (27). This angle is formed by the superomedial point on the $\mathrm{HC}$, the superiormost point along the posterior edge of the $\mathrm{OC}$, and the superiormost point of the medial JT. When the JT and OC are not prominent $\left(\mathrm{JTA}>180^{\circ}\right)$, a transcondylar approach does not significantly increase petroclival or brainstem exposure compared with the condylar fossa approach (27). The measured values of all the above-mentioned structures may help the surgeon in a limited manner, compared to the thorough knowledge of the anatomical variations and the universal landmarks (3$5,7,10,14,15,18)$.
The following points have been demonstrated by the present study: 1) The shape and morphologic variations of the FM are important. In an ovoid type of the FM, the ability of the surgeon to adequately expose the anterior portion of the FM might be difficult. In our study, the shape of the FM varied and the ovoid FM was demonstrated in $58 \%$ of the specimens. An asymmetrical FM was found in $10 \%$ of the specimens, and the hypocondylar arch was found in one of our dry skulls. 2) Protrusion of the $\mathrm{OC}$, morphologic variations and the length of the $\mathrm{OC}$ is another important factor. The present study demonstrated that the OC protruded into the FM in $57 \%$ of the skulls examined. Muthukumar et al. demonstrated that the OC protrudes significantly into the $\mathrm{FM}$ in $20 \%$ of the skulls (14). Protrusion of the OC into FM, especially in the ovoid type of FM, may indicate more extensive bony removal during surgery. The same amount of partial condylectomy may cause greater occipitocervical instability in short OC. It is known that although a 1/3-2/3 resection may not cause craniocervical instability, total resection may lead to the mentioned effect (2). In the present study, short and long OC were determined in $5 \%$ and $33 \%$ of the specimens, respectively. On the other hand, Naderi et al. found that the OC was short in $8.6 \%$ and long in $14.1 \%$ (15). 3) The distance between the $\mathrm{HC}$ and the posterior border of the $\mathrm{OC}$ is critical. This measurement gives an indication about the maximum amount of resectable condyle without entering the HC. This distance was found to be $9.9 \mathrm{~mm}$, on average, in anatomical dry skull measurements. On radiological examination we found the average measurement of this distance to be 10.4 $\mathrm{mm}$. Other authors have found the $\mathrm{HC}$ at an average distance of $12.2 \mathrm{~mm}$ from the posterior margin of the $\mathrm{OC}$ in dry skull measurements (14) and Barut et al. (2) found that this distance to be $12.5 \mathrm{~mm}$ at the right side and $12.6 \mathrm{~mm}$ at the left (2). The present study demonstrated that the $\mathrm{HC}$ was divided into two parts by a bony septum in $30 \%$ of the dry skulls. Septated HCs have been reported on one or both sides in $6 \%$ of the dry skulls (19). Muthukumar et al. showed that the $\mathrm{HC}$ was divided into two by a bony septum in $30 \%$ of the dry skulls(14). 4) Distance of the posterior border of the $\mathrm{OC}$ from opisthion is important because a longer corridor provides a wider space for a far lateral transcondylar approach. In the present study, the average distance was $26.9 \mathrm{~mm}$.

Both extra and intradural JT resection can be performed for lesions of the brainstem to gain a wider exposure. The intradural resection of the JT has been reported and suggested just by three authors including Day (5), Mori K et al. (13) and Salas E et al. (20). They have recommended this procedure especially for some complex vertebral artery and posterior inferior cerebellar artery aneurysms. On the contrary, Mintelis et al. (12) stated that JT drilling must be performed extradurally to avoid any damage to the lower cranial nerves. Day (5) observed that JT resection had provided an operative corridor that was 2 to $4 \mathrm{~mm}$, which was necessary in some cases for adequate visualization of the anterior aspect of the aneurysm neck and the parent vessel. Spektor et al. (23) reported their experience in a cadaveric study regarding the 
extradural JT resection which provided an increased exposure of $28 \%$ to $71 \%$.

There is really dearth of anatomical investigation evaluating the morphometric characteristics of the JT $(12,17)$. Objective anatomical landmarks were suggested for a more precise and reliable assessment by recent studies and length of the JT was reported to be measured between the posterior condylar canal and basilar part of the clivus (12). However, these landmarks may not be constantly present. In our study, posterior condylar foramen was absent unilaterally in $27 \%$ of specimens and bilaterally in $17 \%$ of the specimens. Muthukumar et al. demonstrated that the condylar canal was present in $60 \%$ of the skulls (14). Therefore, the posterior condylar canal may not be used as a constant landmark. We measured the JT length between the anterior and posterior regions where this structure flattens. Mintelis and his colleagues (12) measured the JT width as the distance between the anterior border of the hypoglossal canal and the anterior infrajugular point. The thickness was measured according to the points of the imaginary lines drawn perpendicular to the width and the length.

The present morphological study of the anatomical measurements revealed that the distance of the tip of the JT to the HC, and the height of the JT, was of considerable importance in restricting the vision of the medially located lesion (Figure 12). However, the aforementioned anatomical consideration should not be overemphasized in real life surgery because careful drilling along with thorough anatomical knowledge and surgical experience are irreplaceable.

Radiological measurements were performed for two anatomical structures, OC and JT, that limit the surgical view of the lesions located to the anterior of the FM. Statistical analysis of the anatomical measurements and the corresponding radiological mean values did not show any statistical significance. The similarity of the radiological assessment using 3D CT to the anatomical measurement strengthens the accepted notion that preoperative radiological evaluation is of utmost importance for achieving surgical success.

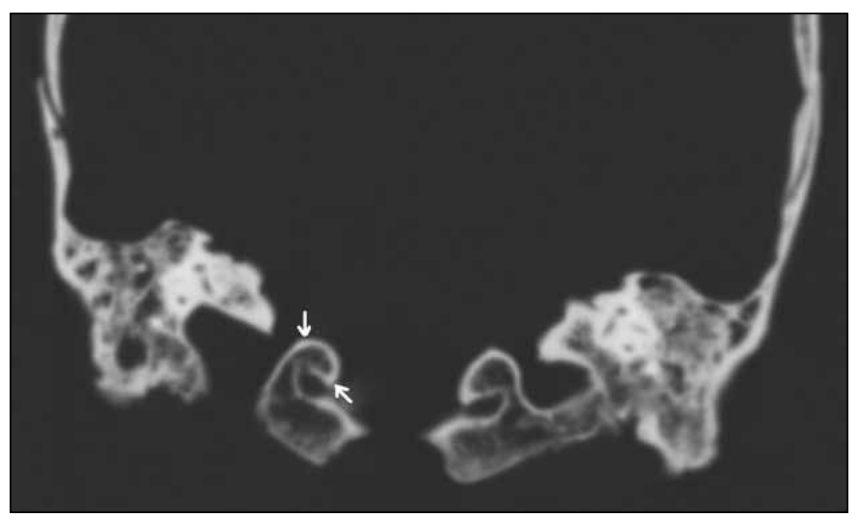

Figure 12: Coronal CT scan shows the height of the JT.

\section{CONCLUSION}

One has to be familiar with the anatomical structures of the FM region and the probable variations of the structures in order to achieve the widest exposure with the best surgical outcome. The OC and JT are the main bony prominences obstructing the anterolateral surface of the brainstem for the far lateral approaches. The statistical insignificance of the radiological and anatomical measurements indicated that the radiological assessment greatly helps to organize the preoperative preparation.

\section{REFERENCES}

1. Al-Mefty O, Borba LA, Aoki N, Angtuaco E, Pait TG: The transcondylar approach to extradural nonneoplastic lesions of the craniovertebral junction. J Neurosurg 84(1):1-6, 1996

2. Barut N, Kale A, Suslu HT, Ozturk A, Bozbuga M, Sahinoglu K: Evaluation of the bony landmarks in transcondylar approach. Brit $J$ of Neurosurgery 23:276-281, 2009

3. Bertalanffy $H$, Seeger W: The dorsolateral, suboccipital, transcondylar approach to the lower clivus and anterior portion of the craniocervical junction. Neurosurgery 29:815-821, 1991

4. Bozbuga M, Ozturk A, Bayraktar B, Ari Z, Sahinoglu K, Polat G, Gurel I: Surgical anatomy and morphometric analysis of the occipital condyles and foramen magnum. Okajimas Folia Anat Jpn 75:329-334, 1999

5. Day JD: Intradural jugular tubercle reduction to enhance exposure via the transcondylar approach: Technical note. Neurosurgery 55:247-250, 2004

6. De Oliveira E, Rhoton AL Jr, Peace D: Microsurgical anatomy of the region of the foramen magnum. Surg Neurol 24:293-352, 1985

7. Dowd GC, Zeiller S, Awasthi D: Far lateral transcondylar approach: Dimensional anatomy. Neurosurgery 45:95-100, 1999

8. Goel A, Desai K, Muzumdar D: Surgery on anterior foramen magnum meningiomas using a conventional posterior suboccipital approach: A report on an experience with 17 cases. Neurosurgery 49:102-106, 2001

9. Heros RC: Lateral suboccipital approach for vertebral and vertebrobasilar artery lesions. J Neurosurg 64:559-562, 1986

10. Lang J: Skull base and Related Structures. Atlas of Clinical anatomy. 2nd ed. Stuttgart/New York: Schattauer, 2001

11. Matsushima $T$, Natori $Y$, Katsuta T, Ikezaki K, Fukui $M$, Rhoton AL: Microsurgical anatomy for lateral approaches to the foramen magnum with special reference to transcondylar fossa (supracondylar transjugular tubercle) approach. Skull Base Surgery 8:119-125, 1998

12. Mintelis A, Sameshima T, Bulsara KR, Gray L, Friedman A.H, Fukushima T: Jugular tubercle: Morphometric analysis and surgical significance. J Neurosurg 105:753-757, 2006

13. Mori K, Nakao Y, Yamamoto T, Maeda M: Intradural jugular tuberclectomy in a case of inadequate extradural removal. Surg Neurol 64:347-350, 2005

14. Muthukumar N, Swaminathan R, Venkatesh G, Bhanumathy SP: A morphometric analysis of the foramen magnum region as it relates to the transcondylar approach. Acta Neurochir (Wien) 147:889-895, 2005 
15. Naderi S, Korman E, Citak G, Guvencer M, Arman C, Senoglu M, Tetik S, Arda MN: Morphometric analysis of human occipital condyle. Clinical Neurology and Neurosurgery 107:191-199, 2005

16. Nanda A, Vincent DA, Vannemreddy PSSV, Baskaya MK, Chanda A: Far-lateral approach to intradural lesions of the foramen magnum without resection of the occipital condyle. J Neurosurg 96:302-309, 2002

17. Osborn AG, Brinton R, Smith WH: Radiology of the jugular tubercles. Am J Roentgenol 131:1037-1040, 1978

18. Prescher A: The craniocervical junction in man, the osseous variations, their significance and differential diagnosis. Ann Anat 179:1-19, 1997

19. Rhoton AL: The foramen magnum. Neurosurgery (Supp) 47: 155-193, 2000

20. Salas E, Sekhar LN, Ziyal IM, Caputy AJ, Wright DC: Variations of the extreme-lateral craniocervical approach: Anatomical study and clinical analysis of 69 patients. J Neurosurg 90:206-219, 1999

21. Seckin $\mathrm{H}$, Ates $\mathrm{O}$, Bauer AM, Baskaya MK: Microsurgical anatomy of the posterior spinal artery via a far-lateral transcondylar approach. J Neurosurg Spin 10(3):228-233, 2009
22. Sen CN, Sekhar LN: Surgical management of anteriorly placed lesions at the craniocervical junction - an alternative approach. Acta Neurochir (Wien) 108:70-77, 1991

23. Spektor S, Anderson GJ, McMenomey SO, Horgan MA, Kellog JX, Delashaw JB Jr: Quantitative description of the far-lateral transcondylar transtubercular approach to the foramen magnum and clivus. J Neurosurg 92:824-831, 2000

24. Spetzler RF, Graham TW: The far-lateral approach to the inferior clivus and the upper cervical region. Technical note. BNI Q 6: 35-38, 1990

25. von Torklus D, Gehle W: The Upper Cervical Spine. London: Butterworths, 1972

26. Wen HT, Rhoton AL Jr, Katsuta T, de Oliviera E: Microsurgical anatomy of the transcondylar, supracondylar, and paracondylar extensions of the far-lateral approach. J Neurosurg 87:555-585, 1997

27. Wu A, Zabramski JM, Jittapiromsak P, Wallace RC, Spetzler RF, Preul MC: Quantitative analysis of variants of the farlateral approach: condylar fossa and transcondylar exposures. Neurosurgery 66(6):191-198, 2010 